\title{
Phylogenetic and morphologic evidence confirm the presence of a new montane cloud forest associated bird species in Mexico, the Mountain Elaenia (Elaenia frantzii; Aves: Passeriformes: Tyrannidae)
}

Zachary R Hanna, Marco F Ortiz-Ramírez, César A. Ríos-Muñoz, Héctor Cayetano-Rosas, Rauri C. K. Bowie, Adolfo G NavarroSigüenza

We here provide evidence to support an extension of the recognized distributional range of the Mountain Elaenia (Elaenia frantzii) to include southern Mexico. We collected two specimens in breeding condition in northwestern Sierra Norte de Chiapas, Mexico. Morphologic and genetic evidence support their identity as Elaenia frantzii. We compared environmental parameters of records across the entire geographic range of the species to those at the northern Chiapas survey site and found no climatic differences among localities. 
1 Phylogenetic and morphologic evidence confirm the presence of a new montane cloud

2 forest associated bird species in Mexico, the Mountain Elaenia (Elaenia frantzii; Aves:

3 Passeriformes: Tyrannidae)

4

5 Zachary R. Hanna ${ }^{1,2,3}$, Marco F. Ortiz-Ramírez ${ }^{4,5}$, César A. Ríos-Muñoz ${ }^{4,6}$, Héctor Cayetano-

6 Rosas $^{4,5}$, Rauri C. K. Bowie ${ }^{1,2}$, Adolfo G. Navarro-Sigüenza ${ }^{4}$

$8{ }^{1}$ Museum of Vertebrate Zoology, University of California, Berkeley, Berkeley, California,

9 United States of America

$10{ }^{2}$ Department of Integrative Biology, University of California, Berkeley, Berkeley, California,

11 United States of America

$12{ }^{3}$ Ornithology \& Mammalogy, California Academy of Sciences, San Francisco, California,

13 United States of America

$14{ }^{4}$ Museo de Zoología, Facultad de Ciencias, Universidad Nacional Autónoma de México,

15 México, Distrito Federal, México

$16{ }^{5}$ Posgrado en Ciencias Biológicas, Universidad Nacional Autónoma de México, México, Distrito

17 Federal, México

$18{ }^{6}$ Unidad de Investigación en Medicina Experimental, Facultad de Medicina, Universidad

19 Nacional Autónoma de México, México, Distrito Federal, México

21 Corresponding Author:

22 Zachary Hanna

23 Email address: zachanna@berkeley.edu 


\section{Abstract}

We here provide evidence to support an extension of the recognized distributional range of the Mountain Elaenia (Elaenia frantzii) to include southern Mexico. We collected two specimens in breeding condition in northwestern Sierra Norte de Chiapas, Mexico. Morphologic and genetic evidence support their identity as Elaenia frantzii. We compared environmental parameters of records across the entire geographic range of the species to those at the northern Chiapas survey site and found no climatic differences among localities.

\section{Introduction}

The Mountain Elaenia (Elaenia frantzii) is a small New World flycatcher that breeds in the high elevation forests of Central America and northern South America and is known to move seasonally to lower elevations (Stiles \& Skutch, 1989). Its distribution has previously been reported to include isolated populations extending from Colombia and Venezuela as far north as north-central Guatemala (Land, 1970; Howell \& Webb, 1995; Eisermann \& Avendaño, 2007), but it has not been documented in Mexico (Peterson \& Chalif, 1973; Hosner, 2004). Its habitat consists of a variety of open humid to semi-humid forest types, including forest edges, secondary growth, and farmland, in an altitudinal range of 750-3600 m. A continuum of fragmented cloud forest extends from the east of the Isthmus of Tehuantepec to the Nicaraguan depression (Ramírez-Barahona \& Eguiarte, 2014), providing potential habitat for this bird in southern Mexico.

We analyzed the morphological and molecular characteristics of two specimens collected in Chiapas, Mexico, during August 2013 and compared them with the associated data from museum specimens of other $E$. frantzii. We additionally investigated environmental parameters 
47 from the previously known distribution of E. frantzii and compared them with those present in southern Mexico to assess the likelihood that suitable conditions exist in southern Mexico to support a resident population of this species.

\section{Methods}

\section{Taxon morphological description}

Elaenia frantzii is a small tyrant flycatcher with a rounded head lacking a coronal patch.

It has dark brown irides and narrow, pale-lemon eye-rings. Its bill is black with a pale, fleshcolored base of the lower mandible and a dusky culmen and tip. The head and upperparts are brownish olive, the throat and chest are grayish olive, and the belly and undertail coverts are pale-lemon. The wing is dusky with conspicuous yellowish wing-bars. The edges of the remiges are yellowish and the tertial edgings are white. The legs are blackish. Males and females have similar external morphology (Howell \& Webb, 1995; Hosner, 2004).

Elaenia frantzii has a patchy distribution throughout the mountain systems of Central and South America. It inhabits open humid to semi-humid forest, forest edges, secondary growth, and farmland areas where scattered bushes and trees are present. Based on geographic distribution and subtle differences in plumage color and body size, four $E$. frantzii subspecies are recognized (Hosner, 2004).

The nominate subspecies, E. f. frantzii Lawrence, 1865, is found in Nicaragua, Costa Rica, and Panama (Hosner, 2004). Elaenia frantzii pudica Sclater, 1871 is overall smaller, darker above, and paler below than the nominate subspecies and inhabits the Andes mountains of northern Colombia and Venezuela (Hosner, 2004). Elaenia frantzii browni Bangs, 1898 is restricted to the Sierra Nevada de Santa Marta of northern Colombia and the Sierra de Perijá of 
northwestern Venezuela and is yet smaller and with paler upperparts than E. frantzii pudica (Hosner, 2004). Elaenia frantzii ultima Griscom, 1935 is a subspecies darker than the nominate inhabiting Guatemala, Honduras and El Salvador and is the most proximately distributed subspecies to southern Mexico (Hosner, 2004). See Figure 3 for a map of the distributions of the subspecies.

Elaenia frantzii can be distinguished from the Yellow-bellied Elaenia (E. flavogaster), a Mexican resident species, by the lack of a white coronal patch, more greenish coloration of the upperparts and less extended yellow in the underparts. Although the coloration is similar to some members of the genus Empidonax, E. frantzii differs from them in its narrow eye-ring and the relative proportions of the body, head and bill.

Study Area

As members of a joint Museum of Vertebrate Zoology (MVZ), University of California, Berkeley and Museo de Zoología “Alfonso L. Herrera” (MZFC), Facultad de Ciencias, Universidad Nacional Autónoma de México team formed to survey the bird, mammal, and herpetological diversity at montane sites in southern Mexico, we traveled to a tract of cloud forest $6.2 \mathrm{~km} \mathrm{~W}$ (by road) from the center of Tapalapa on the road to Coapilla, Municipio Tapalapa, Chiapas, Mexico in August 2013. We sampled the avifauna of the site using mist-nets from 20-24 August 2013 under field permit FAUT-0169 granted by the Mexican government agency Secretaría de Medio Ambiente y Recursos Naturales and with animal ethical approval R317 granted by the UC Berkeley Institutional Animal Care and Use Committee. The mist-nets were 6-12 $\mathrm{m}$ long, $2.5 \mathrm{~m}$ high, and were made of $16 \mathrm{~mm} \times 16 \mathrm{~mm}$ mesh. We preserved a portion of the captured individuals as voucher specimens and deposited them in ornithological research collections at the Museum of Vertebrate Zoology (MVZ) and Museo de Zoología "Alfonso L. 
93

Herrera" (MZFC). We collected tissue samples and assessed the breeding condition of each voucher specimen by measuring gonads and recording any evidence of a brood patch or cloacal protuberance. We also recorded data on molt, fat, skull ossification, and parasite load. After returning from the field, we confirmed the species status of the collected specimens by comparing their preserved external morphologies with individuals deposited in the MZFC.

\section{Bibliographic search}

We conducted all searches described below on 20 December 2014. We performed a literature search for published observations of E. frantzii in Mexico. We additionally searched for records of E. frantzii in VertNet (http://www.vertnet.org), a web-based biodiversity data aggregator. We also searched eBird [(Sullivan et al., 2009), http://www.ebird.org], an online checklist program, which archives lists of bird sightings submitted by professional and amateur birdwatchers, for E. frantzii sightings most proximate to Mexico. As an assessment of whether a lack of documentation of this species in Chiapas, Mexico might be a result of low sampling effort or due to this species having recently expanded its range into Chiapas, we performed a search in VertNet (http://www.vertnet.org) on 20 December 2014 with Record Type = "Any type" and using the following Darwin Core terms: Class = "Aves", Country = "Mexico", and StateProvince $=$ "Chiapas".

\section{Laboratory protocol}

We gathered genetic evidence to support our morphology-based identifications by sequencing 1041 bp of the mitochondrial locus Nicotinamide Adenine Dinucleotide Dehydrogenase Subunit 2 (ND2). We first extracted genomic DNA from $\sim 25 \mathrm{mg}$ of liver tissue using a DNeasy Blood \& Tissue Kit (Qiagen). We then amplified the mitochondrial locus ND2 using the primers L5204 and H6312 (Cicero \& Johnson, 2001). Polymerase chain reaction (PCR) 
116 conditions included an initial denaturation at $94{ }^{\circ} \mathrm{C}$ for $3 \mathrm{~min}$; then 30 cycles at $94{ }^{\circ} \mathrm{C}$ for $30 \mathrm{~s}, 54$

$117{ }^{\circ} \mathrm{C}$ for $30 \mathrm{~s}$, and $72{ }^{\circ} \mathrm{C}$ for $1 \mathrm{~min} 30 \mathrm{~s}$; and a final extension at $72{ }^{\circ} \mathrm{C}$ for $10 \mathrm{~min}$. We sequenced

118 PCR products in both forward and reverse directions using BigDye terminator chemistry

119 (Applied Biosystems) on an ABI 3730 automated sequencer (Applied Biosystems). We edited

120 and constructed consensus sequences using Geneious version 7.1.7 [(Kearse et al., 2012),

121 http://www.geneious.com].

122 Maximum likelihood tree

We retrieved complete ND2 gene sequences for 20 additional individuals representing 10 tyrannid taxa from GenBank (accession numbers appended to the end of taxon names in Figure 4). We aligned sequences using MUSCLE (Edgar, 2004) and constructed a maximum likelihood tree using RAxML version 8.1.20 (Stamatakis, 2014). We used the GTRGAMMA model, searched for the tree with the highest likelihood, and estimated node support using 1000 bootstrap pseudoreplicates.

Environmental characterization and species distribution model

We downloaded all available georeferenced E. frantzii occurrence records from the

131 Global Biodiversity Information Facility (http://www.gbif.org). We constrained our examination of ecological parameters to the area accessible to the species (Peterson et al., 2011). We considered this to be the area from the Isthmus of Tehuantepec, Mexico, to northwestern South America including the Andes Mountains from Ecuador to Northern Venezuela, which is the expanse that includes all vouchered records available for the species. We used a set of 19 bioclimatic variables obtained from the WorldClim project [(Hijmans et al., 2005),

137 http://www.worldclim.org] and five topographic variables; obtained from the Hydrolk project 138 (https://lta.cr.usgs.gov/HYDRO1K), which summed to 24 variables to characterize the 
139

140

141

142

143

144

145

146

147

148

149

150

151

152

153

154

155

156

157

158

159

160

161

environment of the potential distribution of $E$. frantzii (Table 1).

We summarized the ecological variation across the distribution of $E$. frantzii by performing a principal component analysis (PCA) on the values of the 24 ecological variables from the sites of georeferenced $E$. frantzii occurrence records using the package ENMGadgets (Barve \& Barve, 2014) in R version 3.2.2 (R Core Team, 2015). This reduced the multidimensionality of the 24 ecological variables. We then associated all of the records of $E$. frantzii with the PCA output, obtained PCA values for each locality, and plotted PC1 and PC2 of each E. frantzii record.

We employed Maxent 3.3.3k (Phillips, Anderson \& Schapire, 2006) to model the distribution of E. frantzii and assess the suitability of the new Chiapas location as compared with the sites of other E. frantzii occurrences. We used the package raster (Hijmans, 2015) and the implementation of the Pearson correlation index in R version 3.2.2 (R Core Team, 2015) to select a subset of 13 of the 24 bioclimatic and topographic variables with correlation values below 0.85 (Table 1) to avoid over parameterization of the model (Elith et al., 2006; Elith \& Leathwick, 2007). We used the 13 environmental variable subset and all of the georeferenced $E$. frantzii occurrence records in Maxent 3.3.3k (Phillips, Anderson \& Schapire, 2006) to generate ten model replicates (using the subsample replicated run type) using $30 \%$ of the sample records to test the variability produced by a random selection of the training data (random seed). We obtained suitability values from the Maxent model and mapped them along with all of the $E$. frantzii occurrence records using ArcMap 10.0 (ESRI).

\section{Results}

Bibliographic search 
162 163

We found no published observations of E. frantzii in Mexico. The northernmost record of this species in VertNet is a $1.41 \mathrm{~s}$ audio recording of a call from northeast Utah, United States of America made in May 1999 (BLB:Recordings:27930). This record is likely a misidentification or, if not, it documents a vagrant and does not indicate a breeding population as there are no other records of E. frantzii within $3000 \mathrm{~km}$ of this location. The records of E. frantzii closest to Mexico along the land axis of Central America are in southwestern Guatemala (CLO:ML:140002, USNM:Birds:69831, USNM:Birds:80404). The sightings closest to Mexico publicly visible in eBird [(Sullivan et al., 2009), http://www.ebird.org] as of 20 December 2014 were made in July 2001 at $14.7173609^{\circ} \mathrm{N}$ and $91.5309191^{\circ} \mathrm{W}$, WGS84, Santa María de Jesús, Departamento Quetzaltenango, Guatemala (Berry, 2001) and in February 2013 at $15.4769771^{\circ} \mathrm{N}$ and $90.3913987^{\circ} \mathrm{W}, \mathrm{WGS} 84$, Cobán, Departamento Alta Verapaz, Guatemala (Cahill, 2013). Figure 3 includes these records. Our class Aves-based VertNet search indicated that there have been avian records from montane regions in Chiapas from every decade spanning the years 1880-2009, but E. frantzii has never been detected in this region.

\section{Morphological identification}

We surveyed for a total of 283.39 12-m net hours and captured two individuals, which we gave a preliminary designation of $E$. frantzii based on plumage and morphology and assigned to the collector numbers CRH019 and ZRH814. We captured CRH019 on 20 August 2013. It did not display any evidence of molt and was a male in breeding condition with a right testis of $7 \mathrm{x}$ $4.8 \mathrm{~mm}$. We captured ZRH814 on 23 August 2013. ZRH814 was a female in breeding condition with an $8 \times 4 \mathrm{~mm}$ ovary containing two collapsed follicles. It had extensive fat layers, a fully ossified skull, and no evidence of molt.

We deposited a round skin voucher specimen and tissue sample of CRH019 in MZFC as 
185 MZFC:26000. We archived a tissue sample of CRH019 in MVZ as MVZ:Birds:188004. We 186 deposited a round skin voucher specimen and tissue sample of ZRH814 in MVZ as

187 188

MVZ:Birds:188003. We archived a tissue sample of ZRH814 in MZFC as ZRH814.

We confirmed the identity of the Chiapas specimens through comparison with E. frantzii museum skins. Compared with the E. f. frantzii specimen AMNH:Birds:07902 collected in Costa Rica, the newly collected specimens are darker in the upperparts, tail, and wings. The chest and flanks are more olive-colored and darker overall. The edges of the remiges are narrower and contain less yellow. The bill is wider at the distal edge of the nostrils (4 mm in our specimen vs. $3 \mathrm{~mm}$ in the Costa Rica specimen) (Figure 1). These differences are in agreement with the description of the subspecies ultima compared to frantzii (Hosner, 2004).

\section{Molecular identification}

We obtained the complete ND2 gene sequence, $1041 \mathrm{bp}$, from specimens MZFC:26000 and MVZ:Birds:188003, which shared the same ND2 haplotype. We deposited newly generated sequences in GenBank (accession numbers KU312259-KU312260). The maximum likelihood tree grouped the Chiapas E. frantzii ND2 sequence with sequences of E. frantzii from El Salvador and Panama (GenBank accession numbers EU311059 and EU311049, respectively) with 100\% bootstrap support (Figure 4).

\section{Environmental characterization and species distribution model}

The first two principal components of the 24 bioclimatic and topographic variables included $63.24 \%$ of the cumulative ecological variance for the species. The variables which have higher eigenvectors for component 1 are mainly associated with temperature variables whereas those for component 2 are primarily associated with precipitation (Table 1). Values of the environmental variables at the new Chiapas locality fall within the variation of those variables at 
E. frantzii occurrence sites in populations from Central America and South America (Figure 2). We chose the median Maxent model of the ten replicates we generated in order to account for the variation produced by the random selection of sample record seeds in each replicate. The suitability value at the site of the new record of $E$. frantzii in Chiapas is 0.24 . The highest suitability value in our model was 0.87 . The sites of $94 \%$ of the $E$. frantzii records have suitability values greater than or equal to 0.24 (Figure 3). Georeferencing error, sink populations, or vagrant birds may account for a portion of the $E$. frantzii locations situated at sites with low suitability (Peterson et al., 2011).

\section{Discussion}

Morphological and molecular evidence confirm the presence of a breeding population of E. frantzii in Mexico. These records warrant an extension of the range of $E$. frantzii to include the state of Chiapas, Mexico. The closest locality of a publicly available, georeferenced voucher (an audio voucher in this instance) to our new records is $360 \mathrm{~km}$ away (by air) in Guatemala (140002, Macaulay Library Audio and Video Collection, Cornell Lab of Ornithology). Our collection site is $190 \mathrm{~km}$ from the Guatemalan border in the northwestern Sierra Norte de Chiapas at the northern limit of Nuclear Central America (NCA), the area between the Isthmus of Tehuantepec and the Nicaraguan depression (Schuchert, 1935). It is not surprising that $E$. frantzii's range could include the extreme northern portion of NCA as its previously known range includes much of the rest of NCA, across which environmental conditions are largely similar (Ramírez-Barahona \& Eguiarte, 2014). Our ecological niche analyses indicate that climatic conditions where E. frantzii is found in Central and South America are present in Chiapas, Mexico. This distributional pattern of inhabiting cloud forests from Chiapas south through NCA 
231 is exhibited by other species of montane birds, such as Chlorospingus ophthalmicus, Catharus

232 frantzii, and Atlapetes albinucha (Howell \& Webb, 1995), which we also recorded at this

233 locality. After we completed our literature searchers and began to prepare this manuscript, a

234 group of bird watchers visited several sites in the vicinity of our survey site near Tapalapa,

235 Chiapas, México on 7-13 July 2015. The birders sighted multiple Elaenia frantzii (Martinez,

236 2015; Hoyer, 2015) and made several recordings of their calls (Hoyer, 2015a,b,c). These

237 detections indicate that the population that we surveyed appears to be persisting.

238 It is remarkable that this species was previously unknown to Chiapas, despite sampling

239 having been conducted at montane sites in the area over the past century. It is possible that this

240 species has been misidentified in past surveys and collections due to its resemblance to other

241 flycatcher species in the genus Empidonax, whose distributions are known to include Chiapas.

242 Although biological and geological evidence supports the idea of a barrier located at the

243 Motagua-Polochic-Jocotán fault system in central Guatemala with phylogenetic implications for

244 the biota (Morrone, 2001; Gutiérrez-García \& Vázquez-Domínguez, 2013; Ríos-Muñoz, 2013),

245 our limited sampling cannot confirm the existence of a differentiated population in Mexico. We

246 recommend further studies to assess population size and conservation status for this species in

247 Mexico.

248

249

250

251

252

253

\section{Acknowledgements}

We thank the institutions that provided information to the Global Biodiversity

Information Facility. Thank you to the Secretaría de Medio Ambiente y Recursos Naturales for field work authorizations. We are grateful to Sean Rovito for excellent logistical skills that made our field expedition such a success. Thank you to Ana Isabel Bieler Antolín and the Microcine 
254 Lab, Facultad de Ciencias, UNAM for help with the photographs of specimens. Thank you to 255 Michael L. P. Retter for providing feedback on our manuscript and directing us to information 256 concerning the more recent sightings of Elaenia frantzii in Chiapas. Thank you to Willem-Pier

257 Vellinga for directing us to the Xeno-canto recordings from Chiapas. We generated genetic data 258 at the Evolutionary Genetics Laboratory, Museum of Vertebrate Zoology.

259

260

261

262

263

264

265

266

267

268

269

270

271

272

273

274

\section{References}

AMNH:Birds:07902. AMNH Birds. American Museum of Natural History.

Barve N., Barve V. 2014. ENMGadgets: Tools for Pre and Post Processing in ENM workflow. R package version 0.0 .11 .

Berry J. 2001. eBird Checklist:

$<$ http://ebird.org/ebird/camerica/view/checklist?subID=S5135946>. eBird: An online database of bird distribution and abundance [web application]. eBird, Ithaca, New York. Available at $<$ http://www.ebird.org $>$ (Accessed on 20 December 2014).

BLB:Recordings:27930. BLB Recordings. Borror Laboratory of Bioacoustics. Ohio State University, Columbus, Ohio. < http://hymfiles.biosci.ohiostate.edu:8080/ipt/resource.do?r=blb> (Accessed on 20 December 2014).

Cahill J. 2013. eBird Checklist: <http://ebird.org/ebird/view/checklist?subID=S13309447>. eBird: An online database of bird distribution and abundance [web application]. eBird, Ithaca, New York. Available at <http:/www.ebird.org $>$ (Accessed on 20 December 2014). 
275

276

Cicero C., Johnson NK. 2001. Higher-Level Phylogeny of New World Vireos (Aves: Vireonidae) Based on Sequences of Multiple Mitochondrial DNA Genes. Molecular Phylogenetics and Evolution 20:27-40.

Hoyer RC. 2015a. XC256448 Mountain Elaenia (Elaenia frantzii). Accessible at <www.xenocanto.org/256448>.

Hoyer RC. 2015b. XC256449 Mountain Elaenia (Elaenia frantzii). Accessible at <www.xenocanto.org/256449>.

Hoyer RC. 2015c. XC256450 Mountain Elaenia (Elaenia frantzii). Accessible at $<$ www.xenocanto.org/256450>.

CLO:ML:140002. Macaulay Library Audio and Video Collection. Cornell Lab of Ornithology. $<$ http://ipt.vertnet.org:8080/ipt/resource.do?r=cuml_sound_film $>$ (Accessed on 20 December 2014).

Edgar RC. 2004. MUSCLE: multiple sequence alignment with high accuracy and high throughput. Nucleic Acids Research 32:1792-1797.

Eisermann K., Avendaño C. 2007. Lista comentada de las aves de Guatemala: Annotated checklist of the birds of Guatemala. Barcelona, Spain: Lynx Edicions.

Elith J., H. Graham C., P. Anderson R., Dudík M., Ferrier S., Guisan A., J. Hijmans R., Huettmann F., R. Leathwick J., Lehmann A., Li J., G. Lohmann L., A. Loiselle B., Manion G., Moritz C., Nakamura M., Nakazawa Y., McC. M. Overton J., Townsend Peterson A., J. Phillips S., Richardson K., Scachetti-Pereira R., E. Schapire R., Soberón J., Williams S., S. Wisz M., E. Zimmermann N. 2006. Novel methods improve prediction of species' distributions from occurrence data. Ecography 29:129-151.

Elith J., Leathwick J. 2007. Predicting species distributions from museum and herbarium records 
using multiresponse models fitted with multivariate adaptive regression splines. Diversity and Distributions 13:265-275.

Gutiérrez-García TA., Vázquez-Domínguez E. 2013. Consensus between genes and stones in the biogeographic and evolutionary history of Central America. Quaternary Research 79:311-324.

Hijmans RJ., Cameron SE., Parra JL., Jones PG., Jarvis A. 2005. Very high resolution interpolated climate surfaces for global land areas. International Journal of Climatology 25:1965-1978.

Hijmans RJ. 2015. raster: Geographic Data Analysis and Modeling. R package version 2.4-20. $<$ http://CRAN.R-project.org/package=raster $>$.

Hosner PA. 2004. Mountain Elaenia. In: del Hoyo J, Elliott A, Christie DA eds. Handbook of the Birds of the World, Vol. 9. Cotingas to Pipits and Wagtails. Barcelona, Spain: Lynx Edicions, 272-273.

Howell SNG., Webb SW. 1995. A Guide to the Birds of Mexico and Northern Central America. New York: Oxford University Press.

Hoyer RC. 2015. Birdernaturalist: Day 1 of the GBNA Chiapas Field Trips. Available at $<$ http://birdernaturalist.blogspot.com/2015/07/day-1-of-gbna-chiapas-field-trips.html > (Accessed 12 November 2015).

Kearse M., Moir R., Wilson A., Stones-Havas S., Cheung M., Sturrock S., Buxton S., Cooper A., Markowitz S., Duran C., Thierer T., Ashton B., Meintjes P., Drummond A. 2012. Geneious Basic: An integrated and extendable desktop software platform for the organization and analysis of sequence data. Bioinformatics 28:1647-1649.

Land HC. 1970. Birds of Guatemala. Wynnewood, Pennsylvania: Livingston Publishing. 
321 Martinez EA. 2015. eBird Checklist: http://ebird.org/ebird/view/checklist?subID=S24186744.

322

323

324

325

326

327

328

329

330

331

332

333

334

335

336

337

338

339

340

341

342

343

eBird: An online database of bird distribution and abundance [web application]. eBird, Ithaca, New York. Available at $<$ http://www.ebird.org $>$ (Accessed on 12 November 2015).

Morrone JJ. 2001. Biogeografía de América Latina y el Caribe. Zaragoza, España: Sociedad Entomológica Aragonesa.

Peterson AT., Soberón J., Pearson RG., Anderson RP., Martínez-Meyer E., Nakamura M., Araújo MB. 2011. Ecological Niches and Geographic Distributions. Princeton University Press.

Peterson RT., Chalif EL. 1973. A Field Guide to Mexican Birds. Boston, Massachusetts: Houghton Mifflin Co.

Phillips SJ., Anderson RP., Schapire RE. 2006. Maximum entropy modeling of species geographic distributions. Ecological Modelling 190:231-259.

Ramírez-Barahona S., Eguiarte LE. 2014. Changes in the distribution of cloud forests during the last glacial predict the patterns of genetic diversity and demographic history of the tree fern Alsophila firma (Cyatheaceae). Journal of Biogeography 41:2396-2407.

R Core Team 2015. R: A Language and Environment for Statistical Computing. Vienna, Austria: R Foundation for Statistical Computing.

Ríos-Muñoz CA. 2013. ¿Es posible reconocer una unidad biótica entre América del Norte y del Sur? Revista Mexicana de Biodiversidad 84:i-ix.

Schuchert C. 1935. Historical geology of the Antillean-Caribbean region, or the lands bordering the Gulf of Mexico and the Caribbean Sea. J. Wiley \& Sons, Incorporated.

Stamatakis A. 2014. RAxML Version 8: A tool for Phylogenetic Analysis and Post-Analysis of 
Large Phylogenies. Bioinformatics:btu033.

345 Stiles FG., Skutch AF. 1989. A Guide to the Birds of Costa Rica. Ithaca, New York: Cornell University Press.

347

348

349

350

351

352

Sullivan BL., Wood CL., Iliff MJ., Bonney RE., Fink D., Kelling S. 2009. eBird: A citizen-based bird observation network in the biological sciences. Biological Conservation 142:22822292.

USNM:Birds:69831. USNM Birds. National Museum of National History, Smithsonian Institution. $<$ http://ipt.vertnet.org:8080/iptstrays/resource.do?r=nmnh_birds $>$ (accessed on 20 December 2014).

USNM:Birds:80404. USNM Birds. National Museum of National History, Smithsonian Institution. <http://ipt.vertnet.org:8080/iptstrays/resource.do?r=nmnh_birds $>$ (accessed on 20 December 2014). 
1

Ventral, lateral and dorsal views of two Elaenia frantzii.

Panels A-E: a specimen of E. f. frantzii collected in Costa Rica (AMNH:Birds:07902). Panels F-J:

a specimen of E. frantzii collected in Chiapas, México (MZFC:26000). Note the pronounced darker coloration of the Chiapas specimen, especially in the dorsal and lateral views.

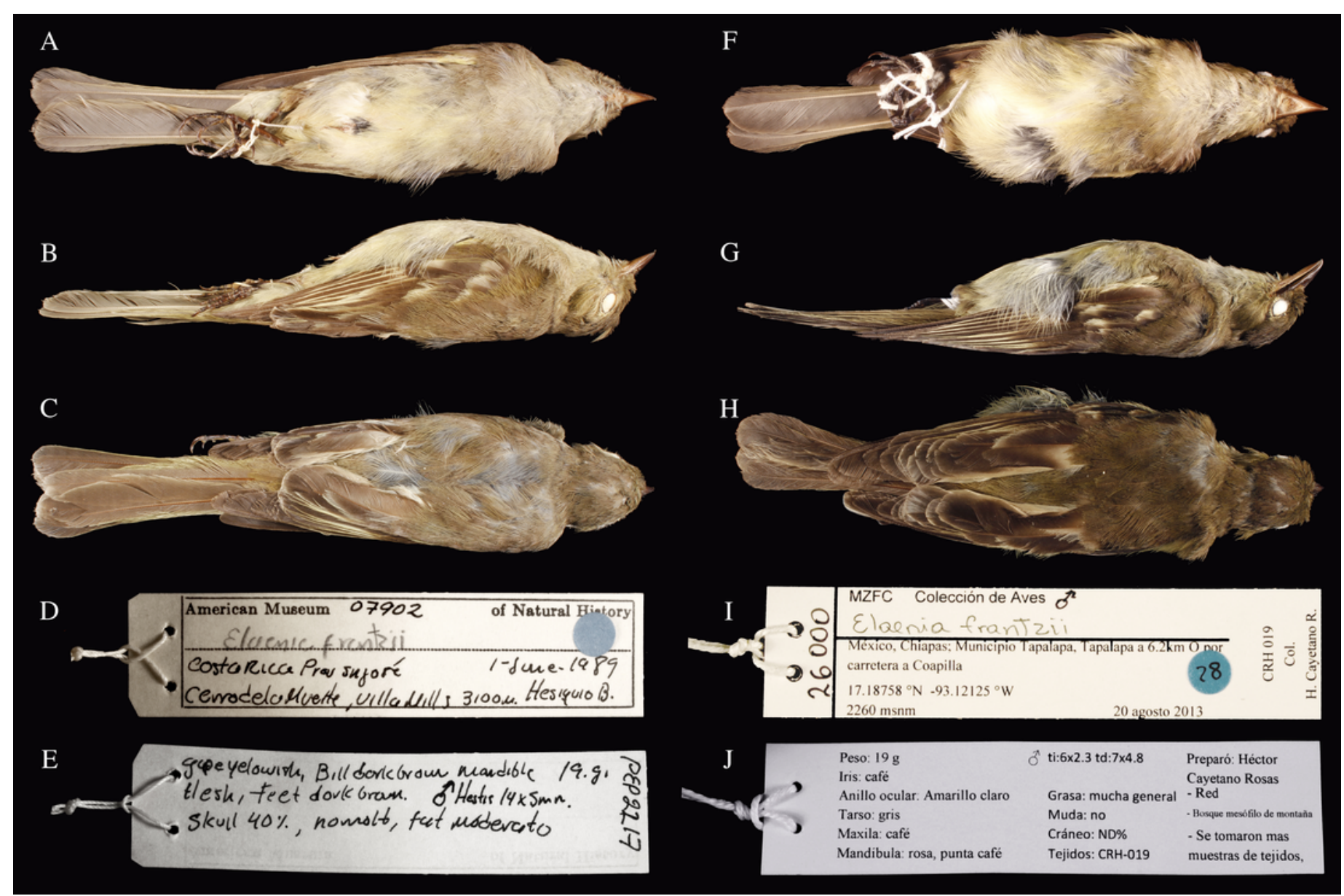


2

Principal components plot of environmental parameters at sites of Elaenia frantzii records.

Green squares: $E$. frantzii browni of extreme northern South America; orange triangles: $E$. $f$. frantzii of Costa Rica and Panama; blue circles: E. frantzii pudica of northern South America; green circles: E. f. ultima of northern Central America; red square: new E. frantzii record from Chiapas, México.

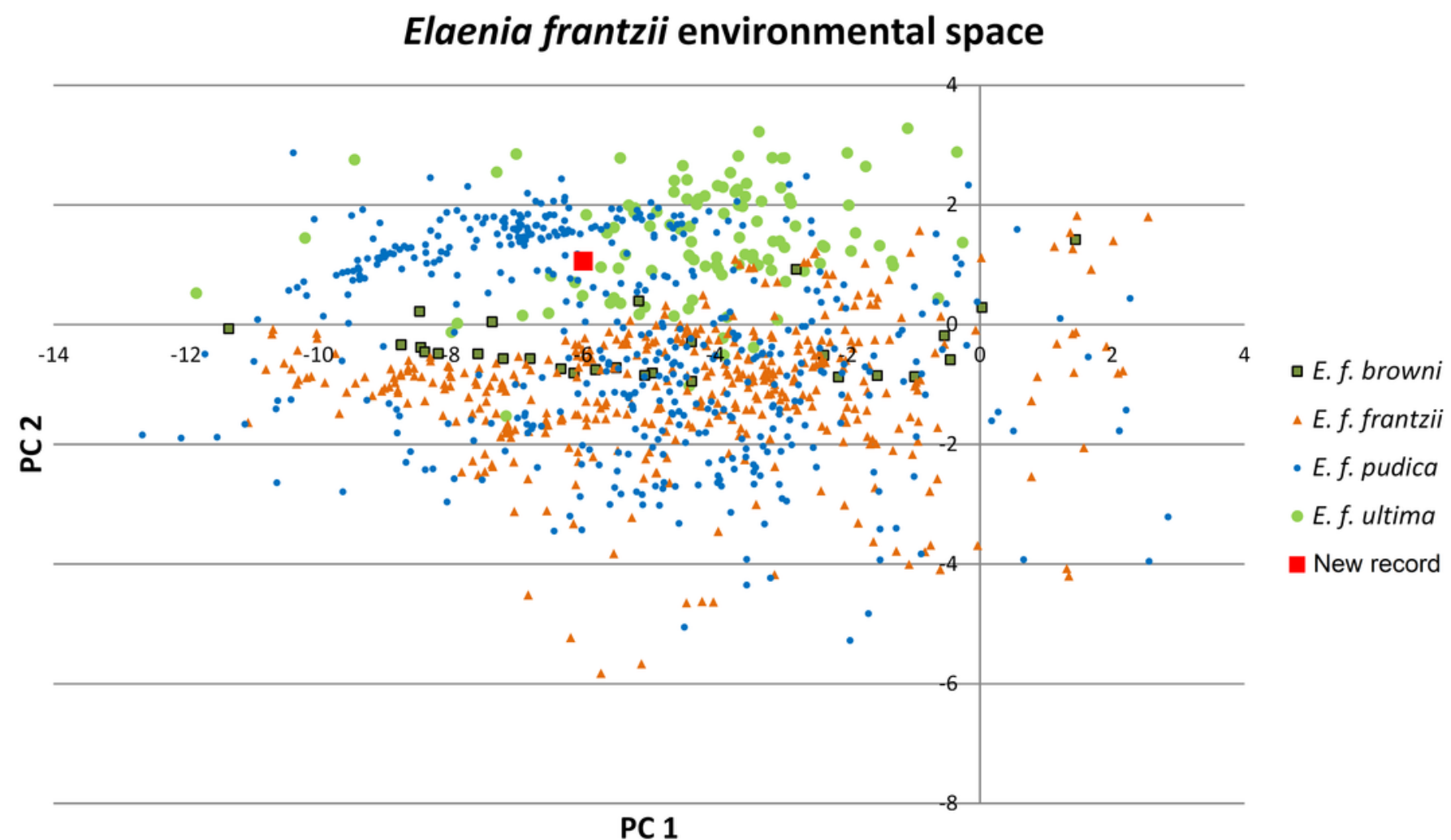


3

Distribution map of Elaenia frantzii with suitability values displayed geographically.

Gray shading indicates the geography of the suitability values predicted by the Maxent model. Darker shades indicate areas with higher suitability while lighter shades denote areas with lower suitability. We have mapped $E$. frantzii records on top of the suitability predictions and color-coded them by subspecies. The red square indicates the site of the new records in Chiapas, Mexico.

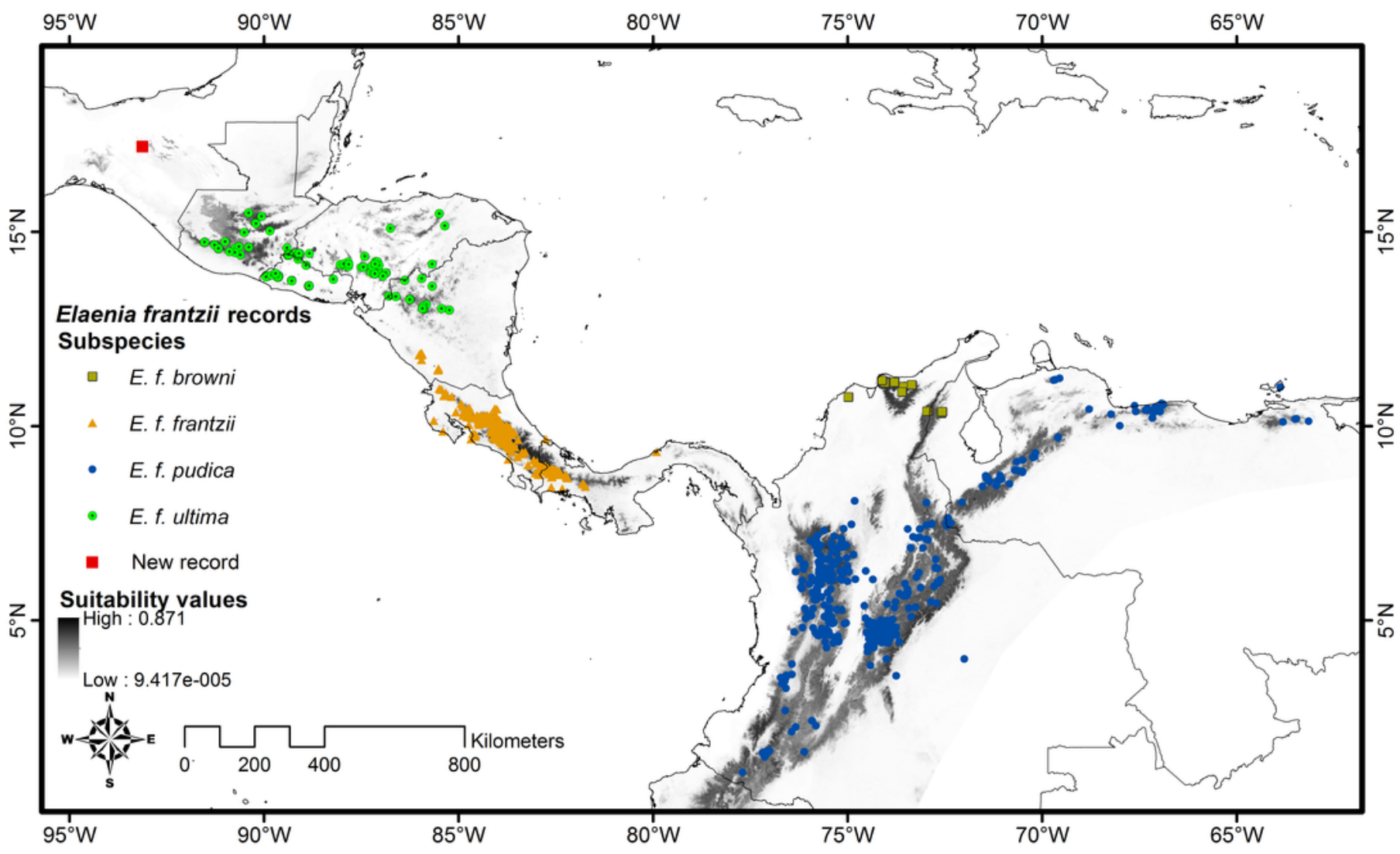




\section{4}

Maximum likelihood topology constructed with ND2 sequences from E. frantzii and other tyrant flycatchers (Tyrannidae).

We have highlighted the $E$. frantzii clade in green. We labeled branches with bootstrap support values (\%) from 1000 pseudoreplicates. Grayed, broken lines denote branches that have been artificially elongated for the sake of clarity in the figure. We rooted the topology with the common ancestor of the Empidonax group. The scale bar indicates the branchlengths that correspond to the maximum likelihood estimate of the number of substitutions that have occurred on average per site between two nodes in the tree. 


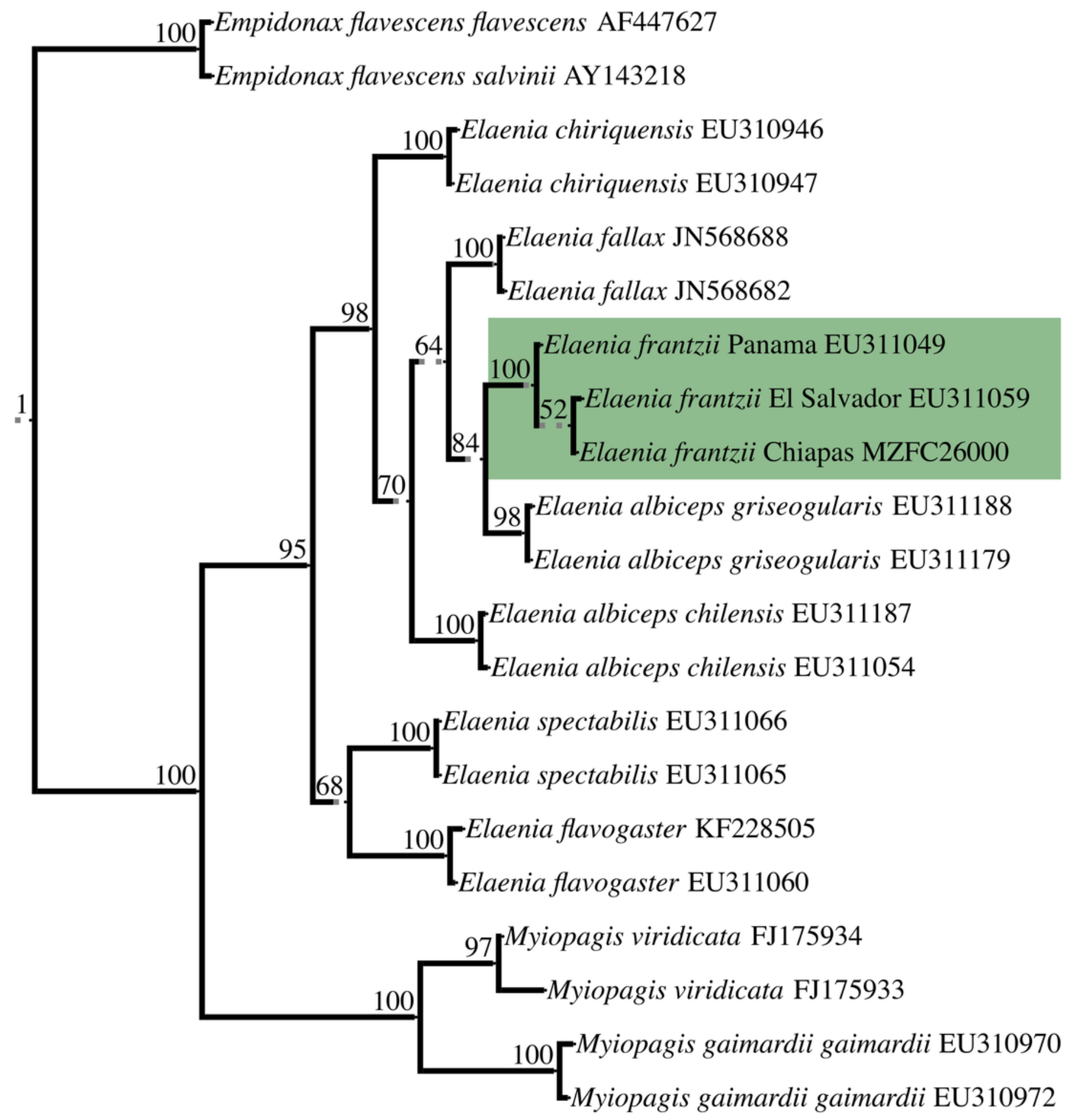

0.12 


\section{Table $\mathbf{1}$ (on next page)}

Environmental variables and their eigenvectors from the principal component analysis (PCA).

PC1 and PC2 refer to the first two principal components of the PCA. We have highlighted the three highest loading values for each principal component in bold. Variables with a trailing asterisk $(*)$ comprise the 13 variables with Pearson correlation index below 0.85 used in the Maxent modeling. 


\begin{tabular}{|c|c|c|}
\hline Original environmental variables & PC1 & $\mathrm{PC} 2$ \\
\hline Annual mean temperature & 3.34E-01 & $2.98 \mathrm{E}-04$ \\
\hline Mean diurnal range & $-2.25 \mathrm{E}-02$ & $1.79 \mathrm{E}-01$ \\
\hline Isothermality & $-1.03 \mathrm{E}-01$ & $-2.05 \mathrm{E}-01$ \\
\hline Temperature seasonality & $8.24 \mathrm{E}-02$ & $1.73 \mathrm{E}-01$ \\
\hline Maximum temperature of warmest month* & $3.27 \mathrm{E}-01$ & $5.96 \mathrm{E}-02$ \\
\hline Minimum temperature of the coldest month* & 3.19E-01 & $-6.72 \mathrm{E}-02$ \\
\hline Temperature annual range* & 4.07E-02 & $2.49 \mathrm{E}-01$ \\
\hline Mean temperature of wettest quarter & $3.31 \mathrm{E}-01$ & $1.41 \mathrm{E}-02$ \\
\hline Mean temperature of driest quarter & 3.32E-01 & $-1.65 \mathrm{E}-02$ \\
\hline Mean temperature of warmest quarter* & 3.35E-01 & $2.15 \mathrm{E}-02$ \\
\hline Mean temperature of coldest quarter* & $3.26 \mathrm{E}-01$ & $-2.53 \mathrm{E}-02$ \\
\hline Annual precipitation* & 4.48E-02 & $-3.66 \mathrm{E}-01$ \\
\hline Precipitation of wettest month* & $7.53 \mathrm{E}-02$ & $-2.92 \mathrm{E}-01$ \\
\hline Precipitation of driest month & $-2.19 \mathrm{E}-02$ & $-3.50 \mathrm{E}-01$ \\
\hline Precipitation seasonality & $8.91 \mathrm{E}-02$ & $2.66 \mathrm{E}-01$ \\
\hline Precipitation of wettest quarter & 7.97E-02 & $-3.05 \mathrm{E}-01$ \\
\hline Precipitation of driest quarter* & $-1.99 \mathrm{E}-02$ & $-3.60 E-01$ \\
\hline Precipitation of warmest quarter & $-4.20 \mathrm{E}-02$ & $-3.04 \mathrm{E}-01$ \\
\hline Precipitation of coldest quarter & 7.19E-02 & $-3.10 \mathrm{E}-01$ \\
\hline Altitude* & $-3.26 \mathrm{E}-01$ & $5.18 \mathrm{E}-03$ \\
\hline Slope* & $-2.29 \mathrm{E}-01$ & $6.67 \mathrm{E}-03$ \\
\hline Eastness slope* & $-7.92 \mathrm{E}-03$ & $-5.50 \mathrm{E}-03$ \\
\hline Northness slope* & $5.48 \mathrm{E}-03$ & 4.93E-03 \\
\hline Topographic index* & $1.83 \mathrm{E}-01$ & $-5.61 \mathrm{E}-03$ \\
\hline
\end{tabular}

